Review Article

\title{
Cyclic Degradation Characteristics of Undisturbed Soft Clay considering Anisotropy
}

\author{
Miaomiao Sun, ${ }^{1}$ Jiangang Yu $\mathbb{D}^{\mathrm{D}},{ }^{1}$ Shaoheng $\mathrm{He}^{,}{ }^{2}$ and Zhi Ding ${ }^{1}$ \\ ${ }^{1}$ Department of Civil Engineering, Zhejiang University City College, 51 Huzhou Street, Hangzhou 310015, China \\ ${ }^{2}$ Research Center of Coastal and Urban Geotechnical Engineering, Zhejiang University, Hangzhou 310058, China
}

Correspondence should be addressed to Jiangang Yu; 31703025@stu.zucc.edu.cn

Received 19 August 2020; Revised 6 September 2020; Accepted 4 February 2021; Published 17 February 2021

Academic Editor: Baozhong Sun

Copyright ( 92021 Miaomiao Sun et al. This is an open access article distributed under the Creative Commons Attribution License, which permits unrestricted use, distribution, and reproduction in any medium, provided the original work is properly cited.

The stress-strain characteristics of soil depend primarily on the previous stress history and stress path, thus related to both the stress magnitude and direction. To have a better understanding of the response of soft clay under heart-shaped stress paths, 18 cyclic hollow cylinders tests were performed on undisturbed Hangzhou soft clay under different cyclic stress ratios, deviatoric consolidation ratios $\left(K_{0}\right)$, and loading frequencies. The result shows that as the vertical dynamic stress amplitude, $K_{0}$ value, and loading frequency increase, the degradation index gradually decreases. Moreover, the degradation index of the soil under the cyclic torsion shear (CTS) test is always higher than that under the cyclic triaxial (CT) test. The increase in the amplitude of the cyclic stress ratio (CSR), $K_{0}$ value, and the decrease in the loading frequency will promote the initial accumulative plastic strain and accelerate the failure rate of the soil sample; it shows that the effects of cyclic stress ratio amplitude, deviatoric consolidation ratios $K_{0}$, and loading frequency on the accumulative plastic deformation of soil cannot be ignored. On the basis of the test results, a logarithmic relationship between the degradation index and the loading frequency is determined. A new empirical formula of accumulative plastic strain degradation of soft clay has been established, and its accuracy has been further verified by test data. The research results can provide theories for predicting and calculating the long-term settlement and deformation of clay foundation.

\section{Introduction}

Recently, a number of basic transportation facilities like railways, subways, and highways have been built on the soft clay layer in the coastal area, such as Hangzhou, an economically developed coastal city in southeast China. However, soft clay has poor physicomechanical property, low bearing capacity, and high sensitivity and permeability and is easy to soften, which are unfavorable to the foundation stability. With the increasing traffic loads, the soft soil foundation will produce large accumulative plastic deformation, which would adversely influence the infrastructure safety and may even lead to engineering accidents $[1,2]$. Taking the river-crossing tunnel section of Hangzhou Metro Line 1 as an example, the accumulative settlement exceeded $60 \mathrm{~mm}$ in the first 12 months after construction, and it has been settled at a rate of 1 to $2 \mathrm{~mm}$ per month [3]. Another example is the Shanghai Metro Line 1, where the cumulative settlement reached $550 \mathrm{~mm}$, especially in the first 5 years of service, there was an excessive unfavorable settlement of $320 \mathrm{~mm}$, and the average monthly settlement rate was $5 \sim 6 \mathrm{~mm}$ [4]. Consequently, it is necessary to research the characteristics of the soft soil foundation under dynamic traffic load.

At present, there are two main methods for deformation analysis of soft clay under cyclic load. One is the dynamic analysis method based on a complex elastoplastic constitutive model [5]. This method is based on the dynamic consolidation equation and the dynamic elastoplastic constitutive model of the soil. The finite element method is used for calculation, and the elastoplastic constitutive model is used to reasonably describe the characteristics of the cumulative deformation and cumulative pore pressure of the soil under cyclic loading. Each step of the cyclic loading process is calculated cyclically. This is more in line with the mechanical mechanism of the mutual influence of soil 
deformation and pore pressure dissipation. The difficulty of this method is that when the number of load cycles reaches tens of thousands or even millions of times, the amount of calculation is huge, which is not practical in engineering. Therefore, it is rarely adopted by scholars. The other is a practical simplification method based on empirical models [6-12]. This method first divides the long-term settlement into two parts, namely, the accumulated settlement caused by plastic deformation in the soil under undrained cyclic loading and the consolidation settlement caused by the dissipation of pore pressure in the soil due to the cyclic load. Then, based on the results of the indoor cyclic triaxial test, the plastic strain and cumulative pore pressure model are obtained. Finally, the layered sum method is used to calculate the long-term settlement of the foundation. The existing empirical models can be divided into the following types. The first model is simple, which mainly explains the influence of cycle times on accumulative deformation [13]. However, the failure to consider the influence of applied stress limits its application. The second model considers the effect of additional stress, but it does not reflect the effect of cycle number on accumulative deformation [14]. The third type of model can describe the variation of accumulative deformation with cycle times and additional stress. However, this kind of model is complicated, and the acquisition of model parameters requires a large number of fitting works $[15,16]$. The experimental parameters in these empirical models are generally obtained by fitting and lack the necessary accumulative deformation analysis. In addition, the physical meaning of the main parameters of the model is still open to question.

The aforementioned research results provide an important reference for better understanding the deformation characteristics of soft soil. However, the above-mentioned results are mainly based on the cyclic triaxial (CT) test. In the cyclic triaxial test, the cyclic load is usually simplified to the cyclic vertical load to study soil deformation under cyclic load $[17,18]$. In actual condition, the direction of principal stress inside the soil body would rotate when subjected to shearing. For example, under the action of traffic load and other loads, the vertical and horizontal stresses on the subgrade soil unit body show periodic changes. Furthermore, the magnitude and direction of shear stress will change with external load, resulting in a continuous rotation of the principal stress axis [19]. Figure 1 presents the stress path caused by the rotation of the principal stress axis under traffic loads. There are few studies on the influence of rotation of the principal stress axis on soft soil deformation [20-22]. Although Wu and Cai carried out a series of hollow torsional shear tests on Wenzhou soft clay and proposed a simplified permanent strain model, the effects of deviatoric consolidation ratios $\left(K_{0}\right)$ and loading frequency $f$ were not considered. Consequently, the deformation features of anisotropic soft clay under cyclic loading have not been fully understood. Another challenging problem is the remarkable variance of the properties of soft soil with in situ geological conditions. Hence, it is essential to research the soft soil in

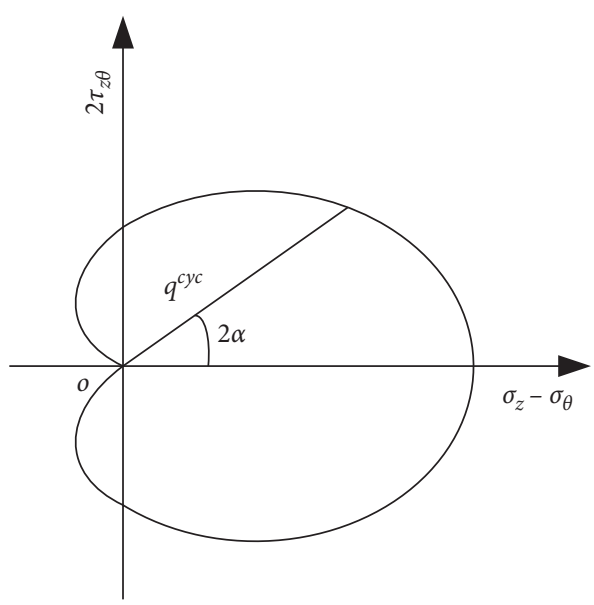

Figure 1: Schematic diagram of stress paths.

different areas to avoid conclusions based on specific sites. Due to the increasing establishment of Hangzhou's infrastructure transportation facilities, in order to ensure the construction and operation of transportation projects, it is necessary to systematically study the dynamic characteristics of soft clay in Hangzhou.

In order to predict the accumulative plastic strain of Hangzhou soft soil under the cyclic torsion shear (CTS) test, 18 tests with different cyclic stress ratios, deviatoric consolidation ratios $\left(K_{0}\right)$, and load frequencies were carried out. The variation of degradation index with cycle numbers was discussed, and the development trend of degradation index of soft clay under the cyclic triaxial test and the cyclic torsion shear test was compared and analyzed. According to the test results, a logarithmic relationship between degradation index and loading frequency was established. The relationship between the degradation index and the accumulative plastic strain under various influencing factors was determined. A new model for predicting the accumulative plastic strain degradation of soft clay is established. The proposed model can provide a theoretical basis for the prediction and calculation of long-term settlement and deformation of foundation soil.

\section{Test Procedure}

2.1. Specimen Preparation. The original soft clay used in the experiment comes from Hangzhou, China. Through the improved special sample preparation equipment (Figure 2), the soil sample was basically undisturbed during the collection process [23]. The quality of the sample in this study was checked according to the study of Lune et al. [24], which verified a good sampling result. Table 1 shows the basic physical properties of Hangzhou clay.

2.2. Test Apparatus. In this research, a dynamic hollow cylindrical torsion shear instrument (GCTS HCA-100) was used to perform the cyclic torsional shear test. The 


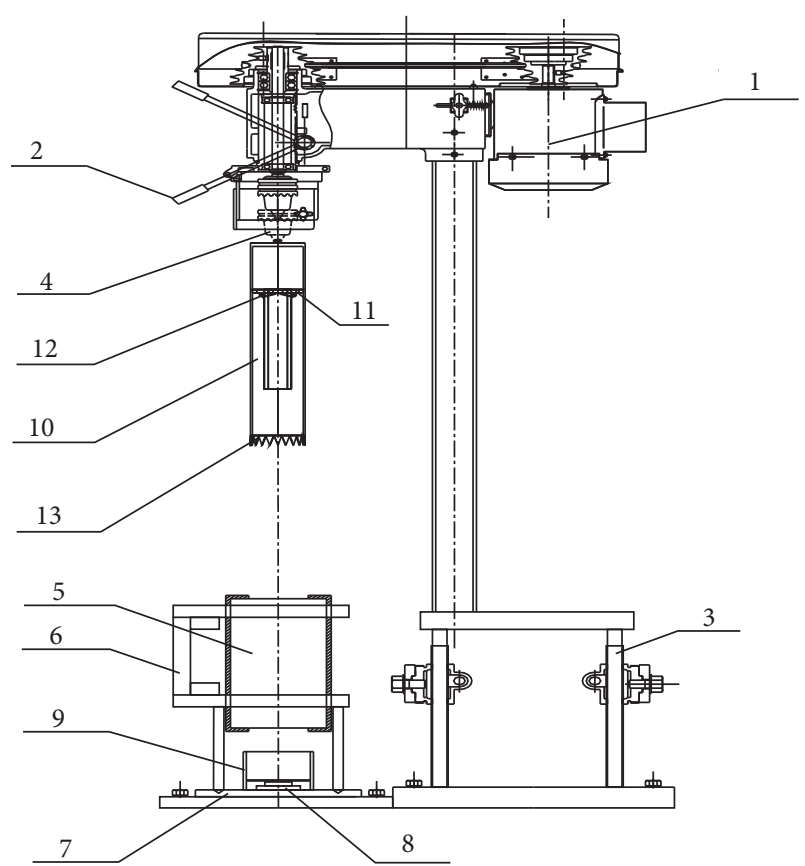

Figure 2: Sketch of the new sample preparation device. The numbers in the figure indicate: 1 . Water drilling rig; 2 . Adjusting handle; 3. Lifting bracket; 4 . Adapter; 5 . Straight rod rotary cutter head; 6. Screw rod cutter head; 7. Sample barrel; 8. Sample barrel support; 9. Bottom turntable; 10. Turntable motor; 11 . Waste soil bucket; 12. Lateral single-opening ring knife; 13. Lateral doubleopening ring knife.

TABle 1: Physical properties of undisturbed soft clay.

\begin{tabular}{lcc}
\hline Property & Variable & Value \\
\hline Natural water content & $\mathrm{w}(\%)$ & 47.00 \\
Dry density & $\mathrm{P}\left(\mathrm{g} / \mathrm{cm}^{3}\right)$ & 11.60 \\
Specific gravity & $G_{\mathrm{s}}\left(\mathrm{g} / \mathrm{cm}^{3}\right)$ & 2.74 \\
Void ratio & $e$ & 1.34 \\
Saturation & $S_{\mathrm{r}}(\%)$ & 96.50 \\
Liquid limit & $W_{\mathrm{L}}(\%)$ & 37.60 \\
Plasticity index & $I_{\mathrm{P}}(\%)$ & 17.56 \\
\hline
\end{tabular}

instrument can independently apply the axial load, torque, internal cell pressure, and external cell pressure to soil samples to simulate different principal stress axis rotation modes (Figure 3(a)). As shown in Figure 3(b), the thinwalled unit body on the sample is subjected to the stress component (the vertical stress $\left(\sigma_{\mathrm{z}}\right)$, radial stress $\left(\sigma_{\mathrm{r}}\right)$, circumferential stress $\left(\sigma_{\theta}\right)$, and torsional shear stress $\left.\left(\tau_{z \theta}\right)\right)$. The specific definition can be seen in Hight et al. [25]. The major principal stress $\left(\sigma_{1}\right)$, intermediate principal stress $\left(\sigma_{2}\right)$, minor principal stress $\left(\sigma_{3}\right)$, and the angle between the principal stress direction and the vertical direction $(\alpha)$ can be subsequently determined and controlled. The relationships between all stresses and strains under different conditions are provided in Table 2.
2.3. Test Program. This paper mainly studies the softening characteristics of intact soft clay under cyclic loading. The test plan is shown in Table 3. During the test, the sample cutter is used to cut the soil sample into the size used for the test, the sample height is $200 \mathrm{~mm}$, the outer diameter is $100 \mathrm{~mm}$, and the inner diameter is $60 \mathrm{~mm}$. Then, the sample is installed into the pressure chamber of the test instrument (HCA). After the installation is completed, in order to obtain a higher degree of saturation, the sample is followed by back-pressure saturation at a back-pressure (the pore water pressure applied by the upper end of the specimen) of $100 \mathrm{kPa}$ with an effective confining pressure of $20 \mathrm{kPa}$ for 48 hours. As the $B$-value (pore pressure coefficient) is better than 0.97 , the sample is considered to be saturated [26]. After the sample is saturated, the sample is consolidated under a confining pressure of $50 \mathrm{kPa}$. The consolidation is divided into two steps. First, the isotropic consolidation is performed, and then the deviator stress $(q)$ is applied to perform the deviator stress consolidation [27, 28].

After the specimen is consolidated, to simulate the actual load conditions (traffic loading) more accurately, the same internal pressures $\left(p_{\mathrm{i}}\right)$ and external pressures $\left(p_{\mathrm{o}}\right)$ are applied during the test. The phase difference between the circulating torque $M_{\mathrm{T}}$ and the circulating axial force $W$ is maintained, and the waveforms of $M_{T}$ and $W$ were imposed (shown in Figure 4). In order to study the influence of load frequency on cyclic behavior, the test loading frequency is set at $0.1 \mathrm{~Hz}$, $0.5 \mathrm{~Hz}$, and $1 \mathrm{~Hz}$.

To facilitate the comparison of test plans, the cyclic stress ratio (CSR) and torsional dynamic stress ratio $(\eta)$ values are defined as follows [29]:

$$
\begin{aligned}
\operatorname{CSR} & =\frac{\sigma_{z}^{\mathrm{ampl}}}{2 p_{0}^{\prime}}, \\
\eta & =\frac{\tau_{z \theta}^{\mathrm{ampl}}}{\sigma_{z}^{\mathrm{ampl}}},
\end{aligned}
$$

where $\sigma_{z}^{\text {ampl }}$ is the vertical dynamic stress amplitude; $p_{0}^{\prime}$ is the initial average principal stress $\left(p_{0}^{\prime}=\left(\sigma_{z 0}^{\prime}+\sigma_{r 0}^{\prime}+\sigma_{\theta 0}^{\prime}\right) / 3 ; \tau_{z \theta}^{\text {ampl }}\right.$ is the dynamic torsion stress amplitude.

\section{Results and Discussion}

3.1. Degradation Index. Figure 5 describes the development of shear stiffness $G$ with cycling number $N$. The figure shows that as the number of cycles increases, the overall shear stiffness gradually decreases. In the first 1000 cycles, the rate of decrease in shear stiffness is faster. At this time, the shear stiffness is approximately linearly related to the number of cycles. With the increasing number of cycles, the attenuation of shear stiffness gradually slows down. It is easy to see that, with the increase in cycle numbers, the sample experienced obvious stiffness degradation. To quantify this degradation, the concept of degradation index $\delta$ was first proposed by Idriss et al. [30]. The degradation index is expressed with the ratio of shear modulus after $N$ loading cycles to the initial value: 


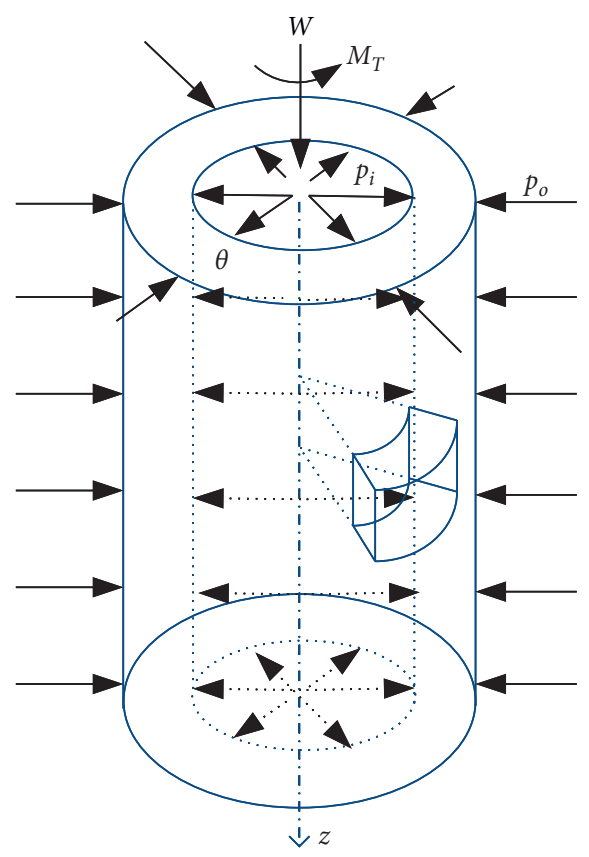

(a)
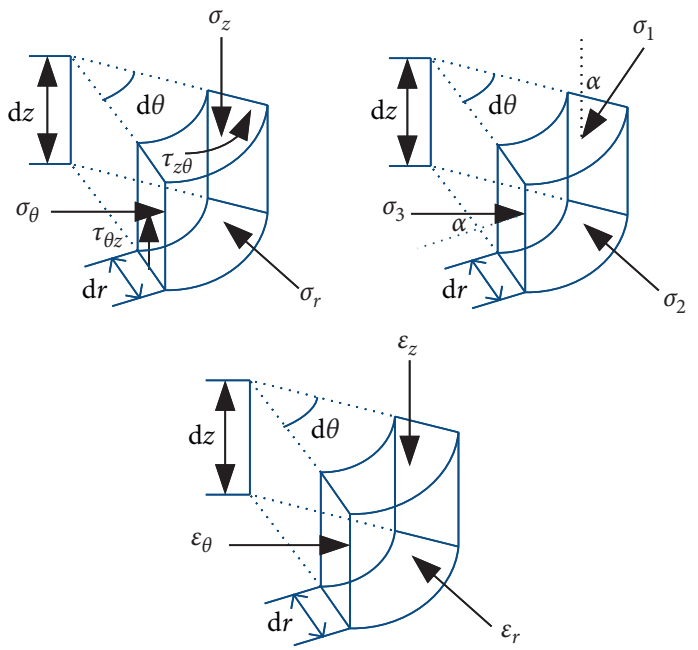

(b)

Figure 3: Thin-walled unit stress state diagram.

TABLE 2: Stress component interpretation equation.

\begin{tabular}{lcr}
\hline & Stress & Strain \\
\hline Circumferential & $\sigma_{\theta}=\left(p_{\mathrm{o}} r_{\mathrm{o}}-p_{\mathrm{i}} r_{\mathrm{i}} / r_{\mathrm{o}}-r_{i}\right)$ & $\begin{array}{c}\varepsilon_{\theta}=-\left(u_{\mathrm{o}}+u_{\mathrm{i}} / r_{\mathrm{o}}+r_{\mathrm{i}}\right) \\
\varepsilon_{\mathrm{r}}=-\left(u_{\mathrm{o}}-u_{\mathrm{i}} / r_{\mathrm{o}}-r_{\mathrm{i}}\right)\end{array}$ \\
Radial & $\sigma_{\mathrm{r}}=\left(p_{\mathrm{o}} r_{\mathrm{o}}+p_{\mathrm{i}} r_{\mathrm{i}} / r_{\mathrm{o}}+r_{i}\right)$ & $\varepsilon_{z}=z / H$ \\
Vertical & $\sigma_{z}=w / \pi\left(r_{o}^{2}-r_{i}^{2}\right)+p_{o} r_{o}^{2}-p_{i} r_{i}^{2} /\left(r_{o}^{2}-r_{i}^{2}\right)$ & $\gamma_{z \theta}=\theta\left(r_{o}^{3}-r_{i}^{3}\right) / 3 H\left(r_{o}^{2}-r_{i}^{2}\right)$ \\
Shear & $\tau_{z \theta}=T / 2\left[3 / 2 \pi\left(r_{o}^{3}-r_{i}^{3}\right)+4\left(r_{o}^{3}-r_{i}^{3}\right) / 3 \pi\left(r_{o}^{2}-r_{i}^{2}\right)\left(r_{o}^{4}-r_{i}^{4}\right)\right]$ & $\varepsilon_{1}=\left(\varepsilon_{z}+\varepsilon_{\theta} / 2\right)+\sqrt{\left(\varepsilon_{z}-\varepsilon_{\theta} / 2\right)^{2}+\gamma_{z \theta}^{2}}$ \\
Major principal & $\sigma_{1}=\left(\sigma_{z}+\sigma_{\theta} / 2\right)+\sqrt{\left(\sigma_{z}-\sigma_{\theta} / 2\right)^{2}+\tau_{z \theta}^{2}}$ & $\varepsilon_{2}=\varepsilon_{\mathrm{r}}$ \\
Intermediate principal & $\sigma_{2}=\sigma_{\mathrm{r}}$ & $\varepsilon_{3}=\left(\varepsilon_{z}+\varepsilon_{\theta} / 2\right)+\sqrt{\left(\varepsilon_{z}-\varepsilon_{\theta} / 2\right)^{2}+\gamma_{z \theta}^{2}}$ \\
Minor principal & $\sigma_{3}=\left(\sigma_{z}+\sigma_{\theta} / 2\right)+\sqrt{\left(\sigma_{z}-\sigma_{\theta} / 2\right)^{2}+\tau_{z \theta}^{2}}$ & - \\
Mean principal stress & $p=1 / 3\left(\sigma_{z}+\sigma_{\theta}+\sigma_{r}\right)$ & $\gamma_{q}=\varepsilon_{1}-\varepsilon_{3}$ \\
Deviatoric stress & $q=\sqrt{\left(\sigma_{z}-\sigma_{\theta}\right)^{2}+4 \tau_{z \theta}^{2}}$ &
\end{tabular}

$$
\delta=\frac{E_{d, N}}{E_{d, 1}}
$$

According to the experimental observation, it can be concluded that the relationship between $\delta_{d}$ and $N$ can be logarithmic [30].

$$
\delta_{d}=N^{-p}
$$

where $p$ is the degradation parameter.

Considering the degradation including the first cycle on the basis of predecessors, the degradation index can be redefined as

$$
\delta=\frac{\left(\sigma_{d, \max }-\sigma_{d, \min } / \varepsilon_{N, \text { max }}-\varepsilon_{N, \min }\right)}{\left(\sigma_{d, \max }-\sigma_{d, \min } / \varepsilon_{1, \max }-\varepsilon_{1, \min }\right)}=\frac{\varepsilon_{1, \max }-\varepsilon_{1, \text { min }}}{\varepsilon_{N, \text { max }}-\varepsilon_{N, \text { min }}},
$$

where $\sigma_{d \text {, max }}$ is the maximum axial stress and $\sigma_{d \text {, min }}$ is the minimum axial stress; $\varepsilon_{1, \max }$ is the maximum axial strain and $\varepsilon_{1, \text { min }}$ is the minimum axial strain in the first cycle; $\varepsilon_{N \text {, max }}$ is the maximum axial strain and $\varepsilon_{N \text {, min }}$ is the minimum axial strain in the $N$ cycle.

3.2. Influence of Cyclic Stress Ratio. Figure 6 shows the relationships in both the degradation index $\delta$ and the dynamic stress amplitude $\sigma_{z}^{\text {ampl }}$ under various numbers of cycles. It can be seen that when the dynamic stress amplitude increases, the degradation index tends to decrease, while as the dynamic stress amplitude increases, the difference is more obvious. The result is similar to that obtained by Cai et al. [20]. Taking the loading frequency of $0.1 \mathrm{~Hz}$ as an example, when the dynamic stress amplitude increases from 0.143 to 0.357 , the degradation index decreases by about $7 \%$. When 
Table 3: Test plan.

\begin{tabular}{|c|c|c|c|c|c|c|c|c|}
\hline Series & Test & Confining pressure $(\mathrm{kPa})$ & $K_{0}$ & $\sigma_{z}^{\mathrm{ampl}}(\mathrm{kPa})$ & $\tau_{z \theta}^{\mathrm{ampl}}(\mathrm{kPa})$ & $\eta$ & CSR & $f(\mathrm{~Hz})$ \\
\hline \multirow{6}{*}{ I } & A101 & 50 & 0.410 & 15 & 6 & 0.4 & 0.15 & \multirow[t]{6}{*}{0.1} \\
\hline & A102 & 50 & 0.410 & 30 & 12 & 0.4 & 0.30 & \\
\hline & A103 & 50 & 0.453 & 30 & 12 & 0.4 & 0.30 & \\
\hline & A104 & 50 & 0.505 & 30 & 12 & 0.4 & 0.30 & \\
\hline & A105 & 50 & 0.410 & 45 & 18 & 0.4 & 0.50 & \\
\hline & A106 & 50 & 0.410 & 45 & 18 & 0.4 & 0.50 & \\
\hline \multirow{6}{*}{ II } & A201 & 50 & 0.410 & 15 & 6 & 0.4 & 0.15 & \multirow[t]{6}{*}{0.5} \\
\hline & A202 & 50 & 0.410 & 15 & 6 & 0.4 & 0.15 & \\
\hline & A203 & 50 & 0.410 & 30 & 12 & 0.4 & 0.30 & \\
\hline & A204 & 50 & 0.410 & 30 & 12 & 0.4 & 0.30 & \\
\hline & A205 & 50 & 0.410 & 45 & 18 & 0.4 & 0.50 & \\
\hline & A206 & 50 & 0.410 & 45 & 18 & 0.4 & 0.50 & \\
\hline \multirow{6}{*}{ III } & A301 & 50 & 0.410 & 15 & 6 & 0.4 & 0.15 & \multirow[t]{6}{*}{1} \\
\hline & A302 & 50 & 0.410 & 15 & 6 & 0.4 & 0.15 & \\
\hline & A303 & 50 & 0.410 & 30 & 12 & 0.4 & 0.30 & \\
\hline & A304 & 50 & 0.410 & 30 & 12 & 0.4 & 0.30 & \\
\hline & A305 & 50 & 0.410 & 45 & 18 & 0.4 & 0.50 & \\
\hline & A306 & 50 & 0.410 & 45 & 18 & 0.4 & 0.50 & \\
\hline
\end{tabular}

Note. $K_{0}$, deviatoric consolidation ratio; $\sigma_{z}^{\text {ampl }}$, vertical dynamic stress amplitude; $\tau_{z \theta}^{\text {ampl }}$, dynamic torsion stress amplitude; $\eta$, torsional dynamic stress ratio; CSR, cyclic stress ratio; $f$, loading frequency.

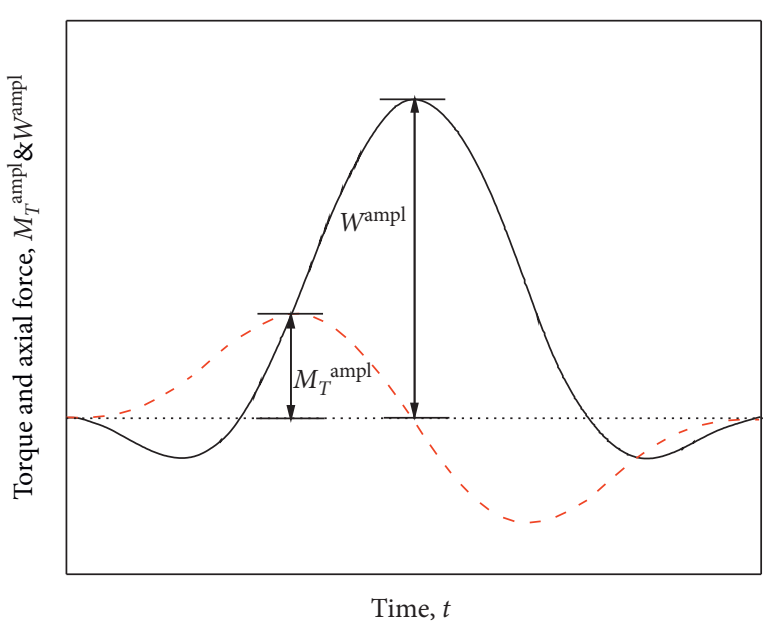

FIGURE 4: Loading waves.

the dynamic stress amplitude increases from 0.357 to 0.538 , the degradation index decreases by about $33 \%$. As the dynamic stress amplitude continues to increase, the sample degradation index reaches a minimum value of 0.57 at 750 cycles, and the soil sample has been destroyed at this time. Consequently, the amplitude of dynamic stress amplitude $\sigma_{z}^{\text {ampl }}$ has a significant effect on the degradation index under cyclic loading.

3.3. Influence of Deviatoric Consolidation Ratio $\left(K_{0}\right)$. The soft soil is characterized by its strong thixotropy, which is a typical reflection of the soil structure. Once disturbed, the flocculent structure would be destroyed, which causes the soil strength to collapse. Consequently, studying the effect of the deviatoric consolidation ratio $K_{0}$ on the degradation index has a certain practical value. Figure 7 shows the

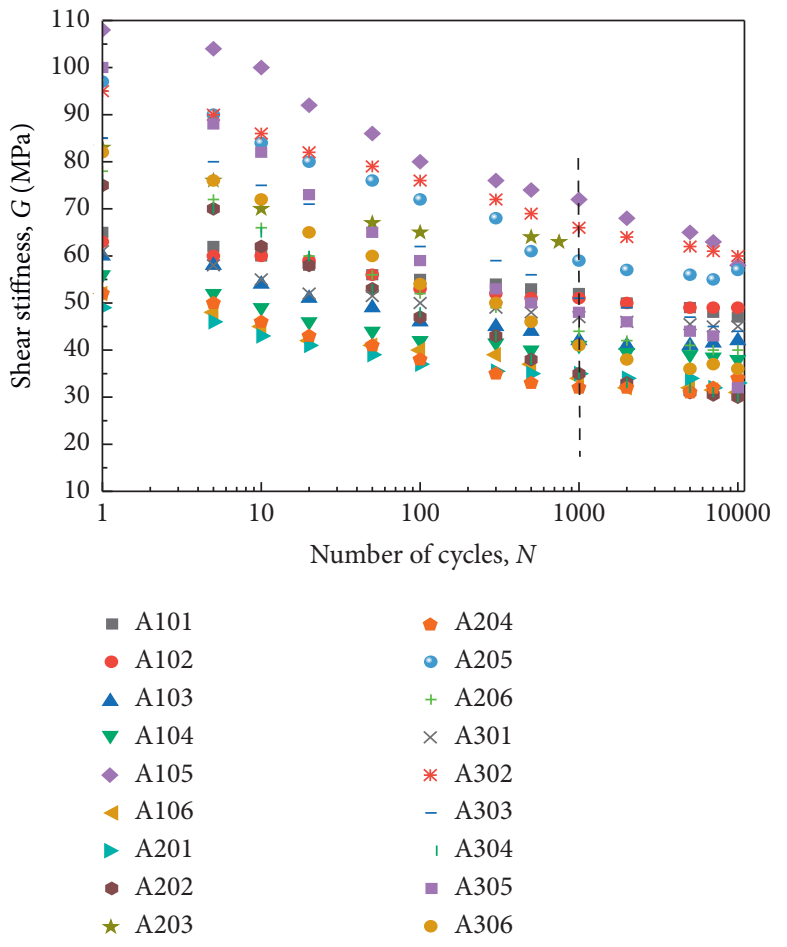

Figure 5: Relationship between shear stiffness and cycle times.

relationships in both the degradation index $\delta$ and the deviatoric consolidation ratio $\left(K_{0}\right)$ value under various numbers of cycles. With the increase in the deviatoric consolidation ratio $\left(K_{0}\right)$ value and the number of cycles, the degradation degree of the soil increases as the degradation index gradually decreases. When the deviatoric consolidation ratio is close to 0.410 , the soil body is destroyed under fewer cycles, and the degradation index presents a 


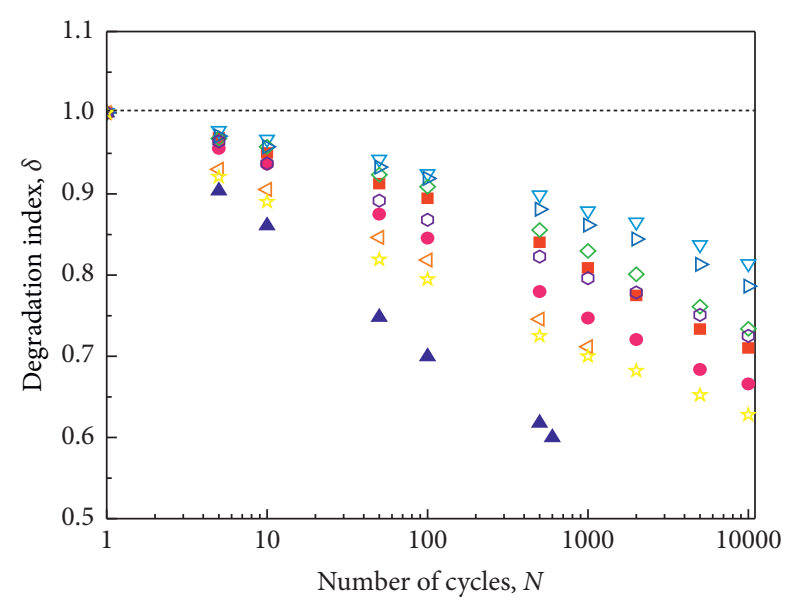

- $f=0.1 \mathrm{~Hz}, \sigma_{z}^{\mathrm{ampl}}=0.143 \triangleleft f=0.5 \mathrm{~Hz}, \sigma_{z}^{\mathrm{ampl}}=0.522$

- $f=0.1 \mathrm{~Hz}, \sigma_{z}^{\mathrm{ampl}}=0.357 \quad \triangleright f=1 \mathrm{~Hz}, \sigma_{z}^{\mathrm{ampl}}=0.170$

\ $f=0.1 \mathrm{~Hz}, \sigma_{z}^{\mathrm{ampl}}=0.538 \quad \circ f=1 \mathrm{~Hz}, \sigma_{z}^{\mathrm{ampl}}=0.258$

$\nabla f=0.5 \mathrm{~Hz}, \sigma_{z}^{\mathrm{ampl}}=0.165 \quad f=1 \mathrm{~Hz}, \sigma_{z}^{\mathrm{ampl}}=0.483$

$\diamond f=0.5 \mathrm{~Hz}, \sigma_{z}^{\mathrm{ampl}}=0.319$

FIGURE 6: Influence of cyclic stress ratio on the development law of degradation index.

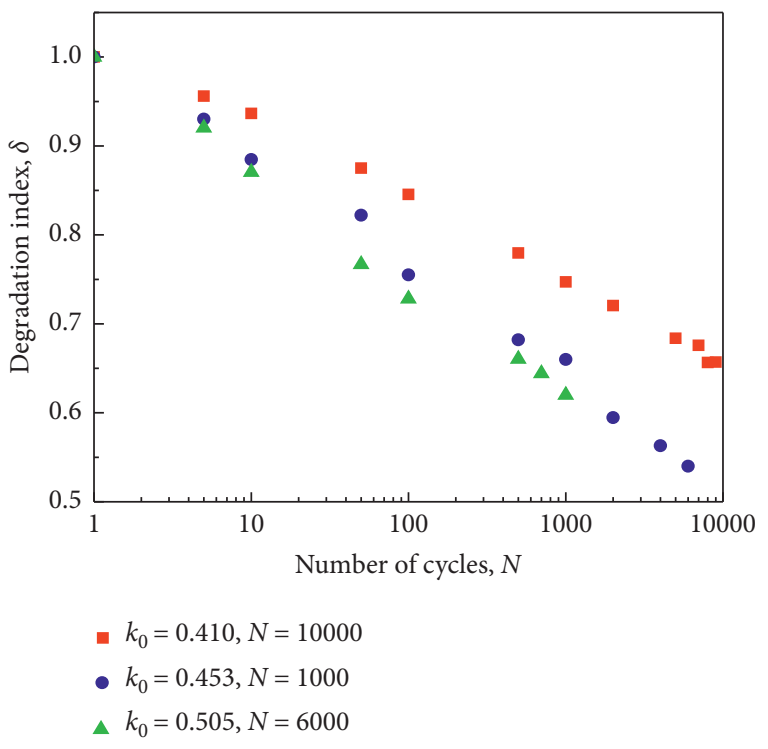

Figure 7: Development of the degradation index when the deviatoric consolidation ratio $\left(K_{0}\right)$ is $0.410,0.453$, and 0.505 .

meaningful downward tendency. This is because when the deviatoric consolidation ratio is small, the dispersion between the soil elements is significant, and a large initial accumulative plastic strain will be generated, which accelerates the destruction of the soil. It can also be seen that when the deviatoric consolidation ratio is reduced from 0.505 to 0.453 , the degradation index is only reduced by less than 3\%, and when the deviatoric consolidation ratio $K_{0}=0.505$ and $K_{0}=0.453$, the developing relationship of the degradation index approaches. It is believed that the

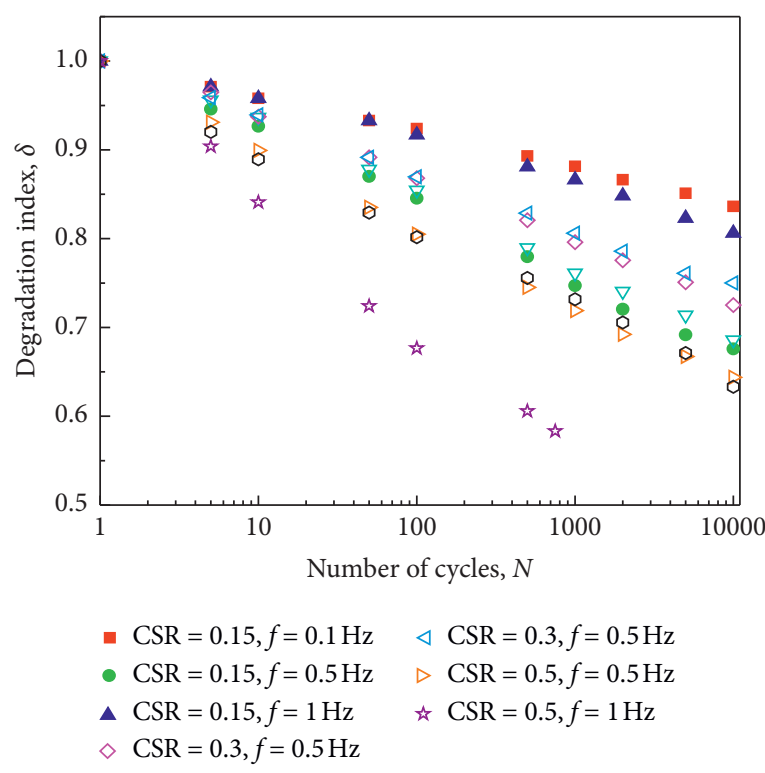

Figure 8: Development of the degradation index under different $f$ values: $f=0.1 \mathrm{~Hz}, f=0.5 \mathrm{~Hz}$, and $f=1 \mathrm{~Hz}$.

influence of the deviatoric consolidation ratio on the degradation index is limited, especially when the deviatoric consolidation ratio $K_{0} \geq 0.453$.

3.4. Influence of Loading Frequency $(f)$. Figure 8 shows the development of the degradation index under the influence of various loading frequencies as the cyclic stress ratio (CSR) is $0.15,0.3$, and 0.5 . With the increase in the number of cycles, the degradation index of the sample shows a decreasing trend. As the cyclic stress ratio is relatively small (around 0.15 ), the samples at different frequencies will not be destroyed, and the attenuation rate of the degradation index gradually decreases as the frequency increases. At this time, the variation of the axial strain is the smallest at a loading frequency of $1 \mathrm{~Hz}$. As the cyclic stress ratio is relatively large $(0.3,0.5)$, with the increasing loading frequency, the declining speed of the degradation index shows an increasing trend; that is, the increase in the loading frequency will accelerate the axial deformation of the sample. In addition, by comparing with the results of Zhou Jian and Gong Xiaonan [31] (the higher the frequency, the lower the degree of soil degradation), when the cyclic stress ratio (CSR) is 0.5 , the degradation index attenuation trend is almost the same, which shows that the loading frequency has little effect on soil degradation characteristics.

3.5. Results of Different Test Methods. Figure 9 presents the development of the degradation index under cyclic triaxial (CT) and cyclic torsion shear (CTS) tests. It is easy to see that the degradation index of the soil under the cyclic torsion shear test is always higher than that under the cyclic triaxial test. This may indicate that the deflection of the principal stress axis will increase the degradation degree of the soil. When the loading frequency $(f)$ is large, the degradation index of the sample under the cyclic triaxial test is greatly 


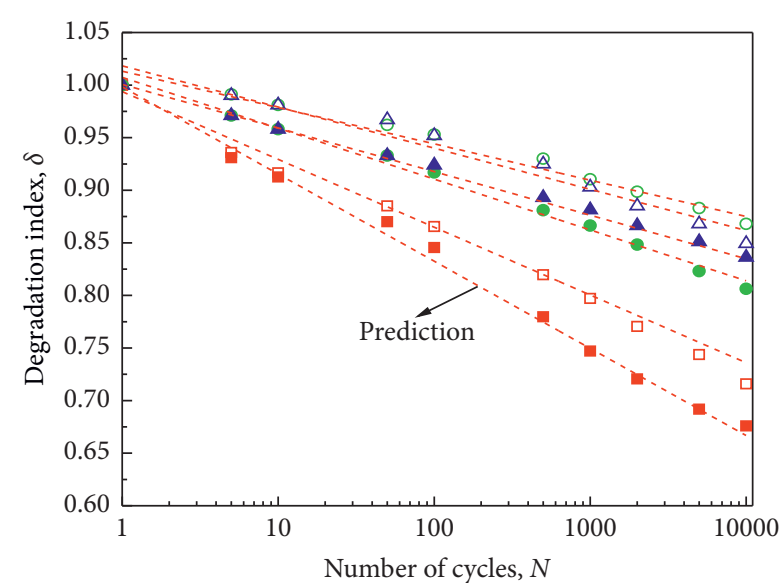

$$
\begin{array}{ll}
\text { - GDS } f=0.1 \mathrm{~Hz} & \text { 口 GCTS-HCA } f=0.1 \mathrm{~Hz} \\
\text { - GDS } f=0.5 \mathrm{~Hz} & \text { ○ GCTS-HCA } f=0.5 \mathrm{~Hz} \\
\text { - GDS } f=1 \mathrm{~Hz} & \triangle \text { GCTS-HCA } f=1 \mathrm{~Hz}
\end{array}
$$

Figure 9: Results under different test methods.

affected by the loading frequency. The specific performance is as follows: when the loading frequency is increased from $0.5 \mathrm{~Hz}$ to $1 \mathrm{~Hz}$, the degradation index is reduced by about $14.4 \%$, and the development trend of the degradation index under the cyclic torsion shear test almost overlaps, and the effect of frequency can be ignored. Moreover, the minimum degradation index of the specimen is different under the two test methods. The cyclic triaxial test is conducted at a loading frequency of $1 \mathrm{~Hz}$, and the hollow torsional shear occurs at a frequency of $0.1 \mathrm{~Hz}$. Therefore, according to the test results, it can be found that, under the same conditions, there is a significant difference in the development law of the degradation index of the soil under the cyclic triaxial and cyclic torsion shear tests. Considering the occurrence of principal stress axis deflection, the hollow torsion shear test is better to describe the degradation characteristics of the soil under actual conditions.

To further study the development law of the degradation index under cyclic triaxial and cyclic torsion shear tests, the following formula is used to fit the relationship in both the degradation index and the number of cycles. The fitting results are shown in Table 4 .

$$
\sigma=a \ln N+b
$$

where $\sigma=$ degradation index; $a, b=$ test parameters.

As shown in Table 4, the ratios of test parameters $a$ and $b$ under the different loading frequencies are almost the same, which are 1.4 and 0.994 , respectively. Considering that the deviation between the fitted curve and the measured relationship is minimal, the ratio of the test parameters obtained by the fitted curve can be approximated as the ratio between the measured relationship function parameters. Hence, when the other conditions are constant, the degradation index under the hollow torsion shear test can be obtained by multiplying the degradation index obtained under the cyclic triaxial test by the corresponding test parameter ratio:

$$
\sigma_{\mathrm{HCA}}=1.4 a \ln N+0.994 b
$$

where $\sigma_{\mathrm{HCA}}$ is the degradation index under the hollow torsion shear test; $a, b$ are the test parameters under the cyclic triaxial test.

3.6. Degradation Index Formulation. Considering that the relationship between the degradation index obtained above and the number of cycles $N$ is approximately linear, a semilogarithmic formula reflecting soil degradation was proposed [32].

$$
\delta_{d}=1-B \ln (N)
$$

where $B$ is the experimental degradation parameter of the soil, which is related to cyclic stress ratio, loading frequency, deviatoric consolidation ratios $\left(K_{0}\right)$, and soil performance; $N$ is the number of cycles. The test parameters of equation (7) are shown in Table 5.

To ensure the accuracy of this equation, considering the impact of the deviatoric consolidation ratios $\left(K_{0}\right)$, the calculated $\delta$ values at loading frequency $f=0.1$ under different $K_{0}$ are compared with the experimental values in Figure 10, where a right prediction is provided.

\section{Relationship between Permanent Strain and Degradation Index}

The relationships between cyclic stress ratio (CSR) and degradation index $\delta$ versus accumulative plastic strain $\varepsilon_{p}$ are plotted in Figure 11. As shown in Figure 12, the degradation index $\delta$ gradually decreases as the accumulative plastic strain increases. The law of degradation index with accumulated strain can be roughly divided into the following stages: when the accumulative plastic strain $\varepsilon_{p}$ is less than $0.01 \%$, the decay rate of the degradation index is relatively slow, especially when the dynamic stress amplitude $\sigma_{z}^{\text {ampl }}$ is small; this is because the soil sample is in the stage of elastic deformation during the initial loading. The accumulated plastic strain generated is not large, and no significant strain accumulation phenomenon occurs. These similar trends were also observed by Sun et al. [22]. When $\varepsilon_{p}$ is between $0.01 \%$ and $0.8 \%$, the decay rate of the degradation index of the sample increases sharply, and the relationship between the degradation index and the accumulative plastic strain $\left(\lg \varepsilon_{p}\right)$ is approximately linear $[33,34]$; this is more obvious when the dynamic stress amplitude $\sigma_{z}^{\text {ampl }}$ exceeds 0.319 ; when the accumulated plastic strain $\varepsilon_{p}$ exceeds $0.8 \%$, the attenuation of the degradation index gradually slows down with the increase in the accumulative plastic strain. When the accumulated plastic strain reaches around $0.8 \%$, the degradation index changes abruptly, which is represented by the degradation index and the accumulative plasticity. There is a clear inflection point in the strained relationship, which indicates that the soil sample begins to fail at this time. It can also be seen that increasing the dynamic stress amplitude increases the initial accumulative plastic strain of the soil sample, and the accumulative plastic strain generated by the soil body develops rapidly and accelerates the destruction of 
TABle 4: Test parameters.

\begin{tabular}{|c|c|c|c|c|c|c|}
\hline Series & $f(\mathrm{~Hz})$ & $a$ & $\begin{array}{c}\text { The ratio of } \\
\text { parameter } a(\mathrm{CT} / \mathrm{CTS})\end{array}$ & $b$ & $\begin{array}{c}\text { The ratio of } \\
\text { parameter } b(\mathrm{CT} / \mathrm{CTS})\end{array}$ & $\begin{array}{l}\text { Correlation } \\
\text { coefficient } R^{2}\end{array}$ \\
\hline Cyclic triaxial $(\mathrm{CT})$ & 0.1 & -0.038 & \multirow[b]{2}{*}{1.407} & 0.9938 & \multirow{2}{*}{0.995} & 0.992 \\
\hline Cyclic torsion shear (CTS) & 0.1 & -0.027 & & 0.9983 & & 0.993 \\
\hline Cyclic triaxial $(\mathrm{CT})$ & 0.5 & -0.021 & \multirow{2}{*}{1.4} & 1.0073 & \multirow{2}{*}{0.994} & 0.994 \\
\hline Cyclic torsion shear (CTS) & 0.5 & -0.015 & & 1.0132 & & 0.992 \\
\hline Cyclic triaxial $(\mathrm{CT})$ & 0.5 & -0.0236 & \multirow{2}{*}{1.388} & 1.0006 & \multirow{2}{*}{0.994} & 0.994 \\
\hline Cyclic torsion shear (CTS) & 1 & -0.017 & & 1.0062 & & 0.994 \\
\hline
\end{tabular}

TABLE 5: Test parameters.

\begin{tabular}{lcccc}
\hline Series & $f(\mathrm{~Hz})$ & CSR & $B$ & Correlation coefficient $R^{2}$ \\
\hline A101 & 0.1 & 0.15 & 0.0404 & 0.999 \\
A201 & 0.5 & 0.15 & 0.0843 & 0.997 \\
A301 & 1 & 0.15 & 0.0484 & 0.993 \\
A102 & 0.1 & 0.3 & 0.0877 & 0.993 \\
A103 & 0.1 & 0.3 & 0.1221 & 0.994 \\
A104 & 0.1 & 0.3 & 0.1279 & 0.994 \\
A203 & 0.5 & 0.3 & 0.0698 & 0.998 \\
A303 & 1 & 0.3 & 0.0643 & 0.999 \\
tA105 & 0.1 & 0.5 & 0.0893 & 0.997 \\
A205 & 0.5 & 0.5 & 0.0859 & 0.994 \\
A305 & 1 & 0.5 & 0.1477 & 0.991 \\
\hline
\end{tabular}

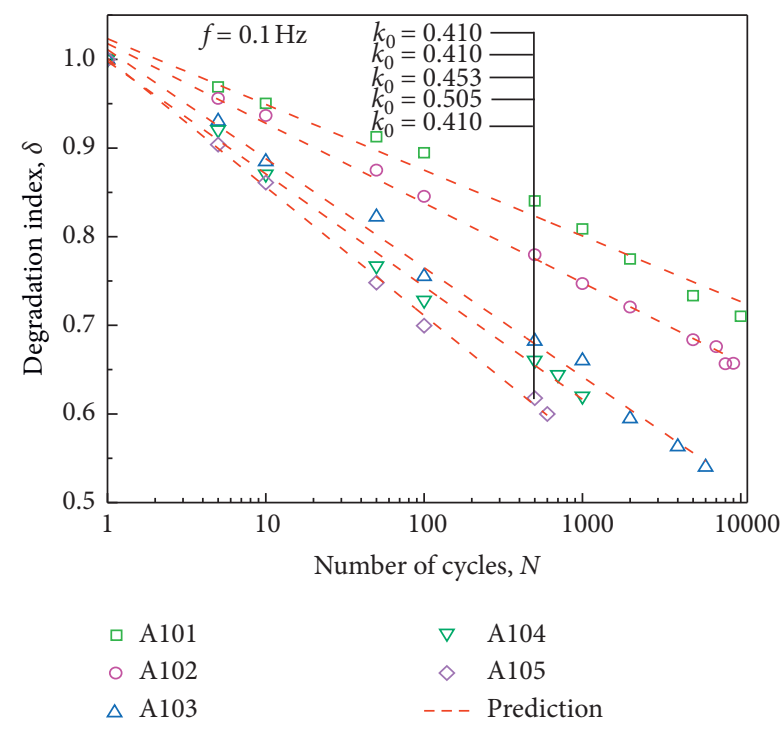

Figure 10: Comparison of the measured value and predicted value.

the soil sample. As the accumulative plastic strain continues to increase, the soil is significantly destroyed. At this time, the relationship between $\delta$ and the accumulative plastic strain $\left(\lg \varepsilon_{p}\right)$ no longer changes with the vertical dynamic stress amplitude.

Figure 12 presents the development rule of the relationship in both the degradation index and accumulative plastic strain under different deviatoric consolidation ratios $\left(K_{0}\right)$ values. It can be shown that as the deviatoric

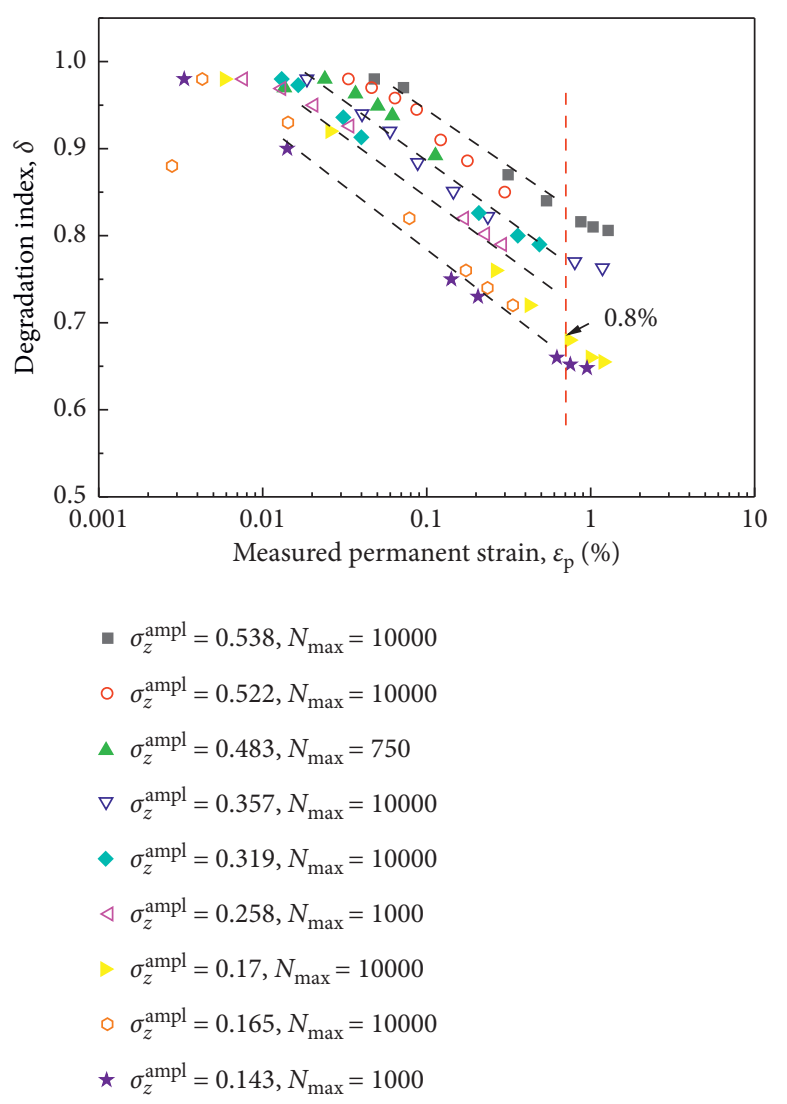

FIGURE 11: Relationship of the cyclic stress ratio (CSR) and $\delta$ versus $\varepsilon_{p}$. 


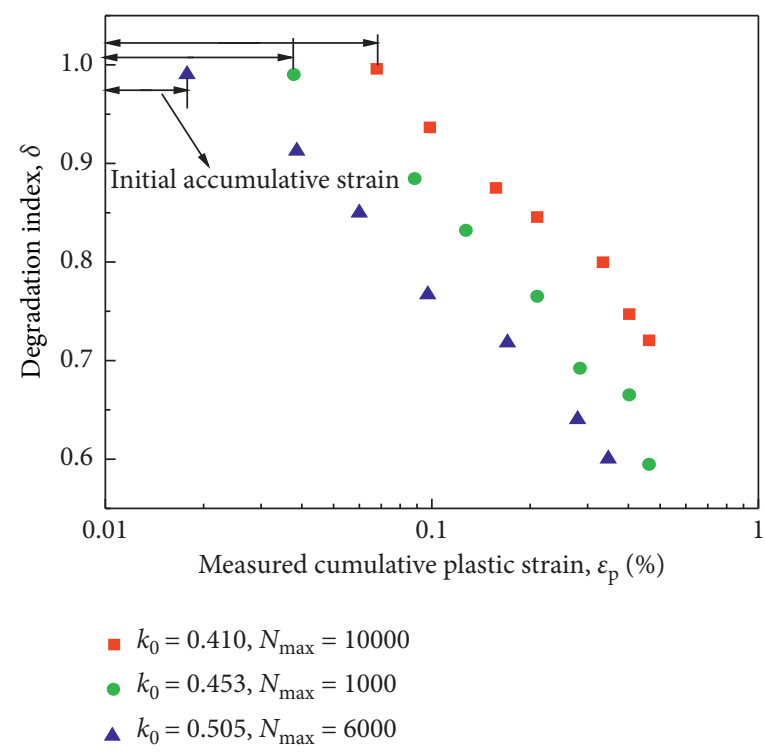

Figure 12: Relationship of $K_{0}$ and $\delta$ versus $\varepsilon_{p}$.

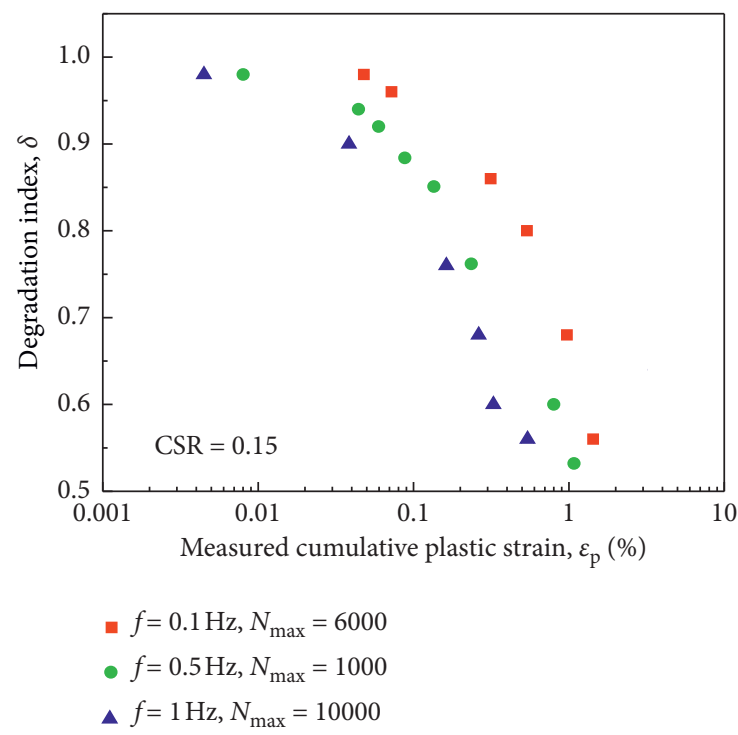

(a)

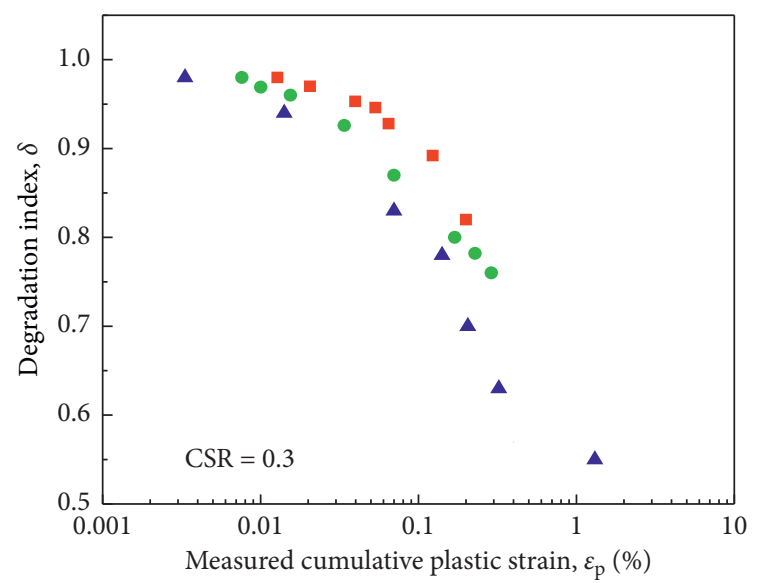

- $f=0.1 \mathrm{~Hz}, N_{\max }=10000$

- $f=0.5 \mathrm{~Hz}, N_{\max }=1000$

\ $f=1 \mathrm{~Hz}, N_{\max }=10000$

(b)

FIgURE 13: Continued. 


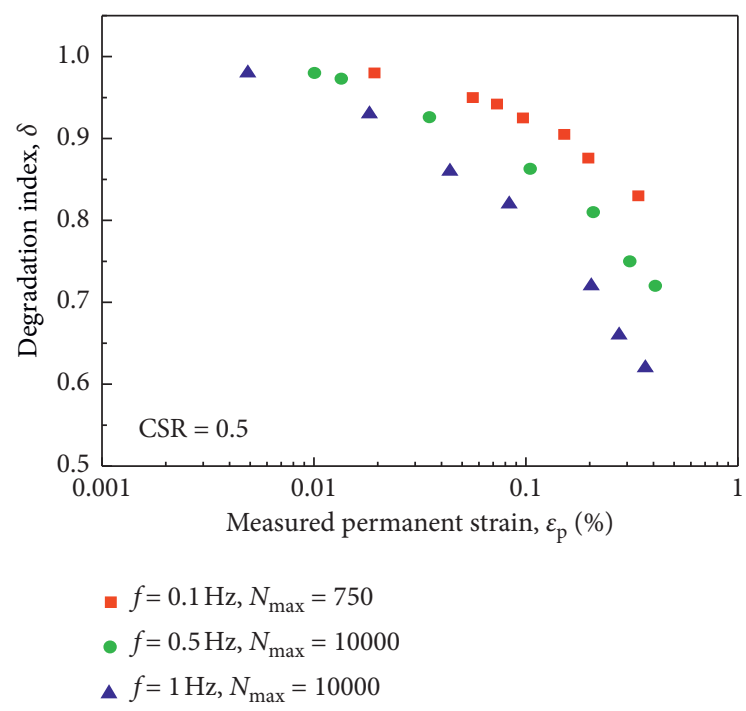

(c)

FIGURE 13: Relationship of $f$ and $\delta$ versus $\varepsilon_{p}$ under different cyclic stress ratios (CSR): (a) CSR $=0.15$, (b) CSR $=0.3$, and (c) CSR $=0.5$.

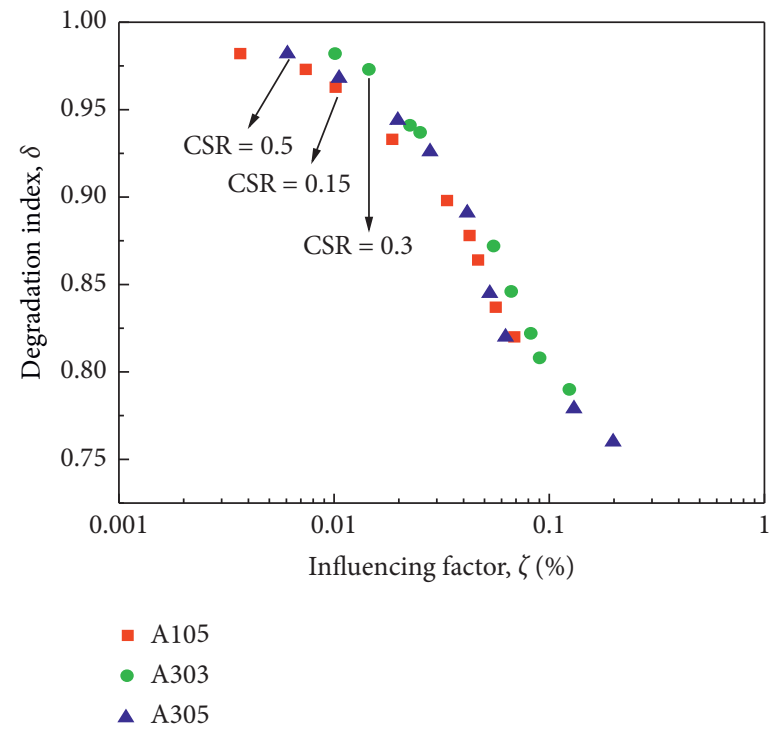

FIGURE 14: Relationship of the degradation index $\delta-\zeta$ for different cyclic stress ratios (CSR).

consolidation ratio increases, the initial accumulative strain of the soil gradually decreases (see the double arrow on the picture), and the development rate of the accumulative plastic strain decreases significantly. In addition, the increase in the deviatoric consolidation ratios speeds up the decreasing trend of the soil degradation index; as the deviatoric consolidation ratio increases, the destruction rate of the soil sample slows down, and the strength degradation of the soil is not apparent at this time.

So far, there is no unified conclusion about the influence of loading frequency on the mechanical properties of soft clay in the geotechnical field [35]. Some scholars think that the development rate of axial strain is influenced by loading frequency [31], and other scholars hold that loading frequency $f$ has little effect on the dynamic characteristics of soft clay [36]. Figure 13 shows the development of degradation index $\delta$ versus accumulative plastic strain $\varepsilon_{p}$ under different loading frequencies $f$. As shown in Figure 14, as the loading frequency decreases, the accumulative plastic strain growth rate of the soil increases, which is also obtained by Matsui [37]; especially when the loading frequency is $0.1 \mathrm{~Hz}$, the initial accumulative plastic strain is the largest, and the corresponding soil failure rate is faster. When the loading frequency is large $(f=0.5 \mathrm{~Hz}, 1 \mathrm{~Hz})$, it can be found from Figures $8(\mathrm{a})-8$ (c) that as the loading frequency increases, the relationship between $f$ and $\varepsilon_{p}$ gradually approaches. This shows that when the frequency is small $(f=0.1 \mathrm{~Hz})$, the frequency has a significant influence on the relationship between $f$ and $\varepsilon_{p}$. When the frequency is high $(f=0.5 \mathrm{~Hz}, 0.1 \mathrm{~Hz})$, it is limited. 


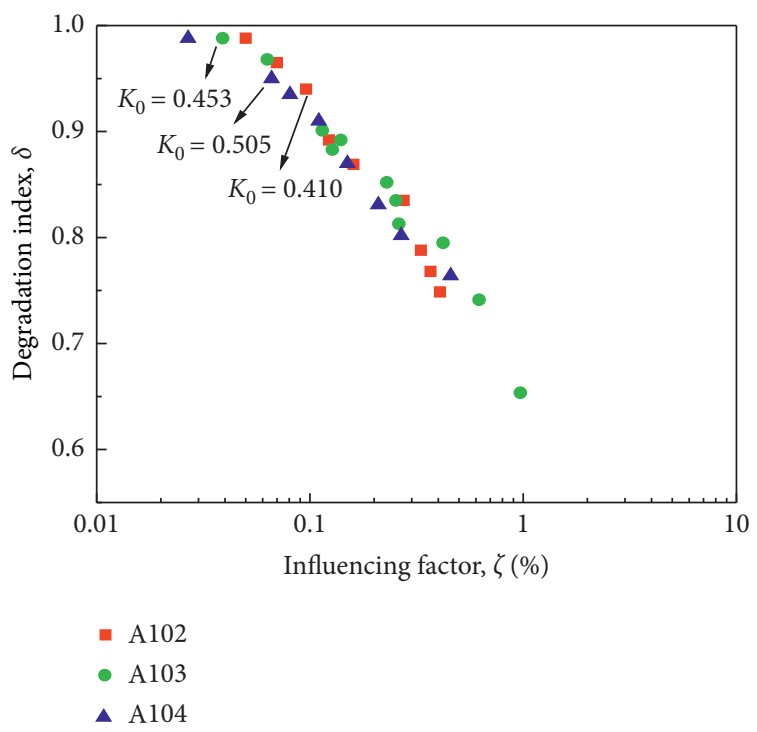

Figure 15: Relationship of the degradation index $\delta-\zeta$ for different $K_{0}$ values.

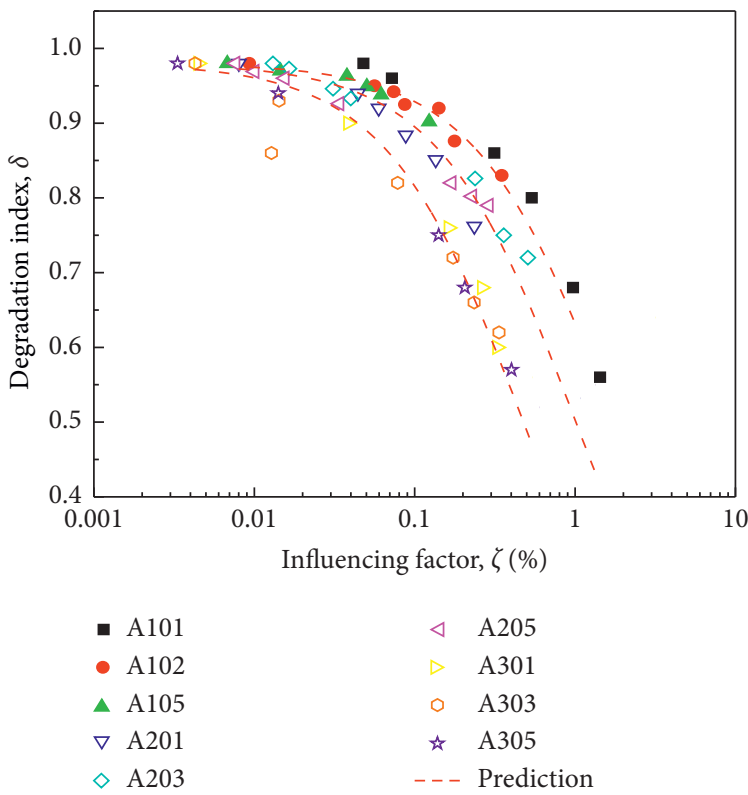

Figure 16: Relationship of the degradation index $\delta-\zeta$ for different loading frequencies $f$.

According to the foregoing analysis, with the increase in the cyclic stress ratio (CSR) and the decrease in the deviatoric consolidation ratios, the initial accumulative strain of the soil gradually increases, and the relationship between the degradation index and the accumulative plastic strain shows a gradual shift to the right. Therefore, the accumulative plastic strain influencing factor $\zeta$ is introduced to comprehensively consider the impact of the cyclic stress ratio (CSR) and deviatoric consolidation ratios $\left(K_{0}\right)$ on the accumulative plastic strain. The analysis of the test results defines the accumulative plastic strain influence factor $\zeta$ as

$$
\zeta=\frac{(1-m \lg f) K_{0}^{n} \varepsilon_{p}}{\operatorname{CSR}}
$$

where $m=1.156, n=2.996$

Figures 14 and 15 show the relationship of the degradation index $\delta-\zeta$ for different cyclic stress ratios (CSR) and different deviatoric consolidation ratios. As shown, most points are concentrated around one set.

To directly reflect the effect of frequency on the degradation characteristics of clay, equation (10) (Parr, 1972) is used to perform regression analysis on the $\delta-\zeta$ relationship in Figure 16, and the expression could be written as

$$
\lg \left(\frac{\dot{\varepsilon_{N}}}{\dot{\varepsilon_{1}}}\right)=\lg C+\varsigma \lg N
$$




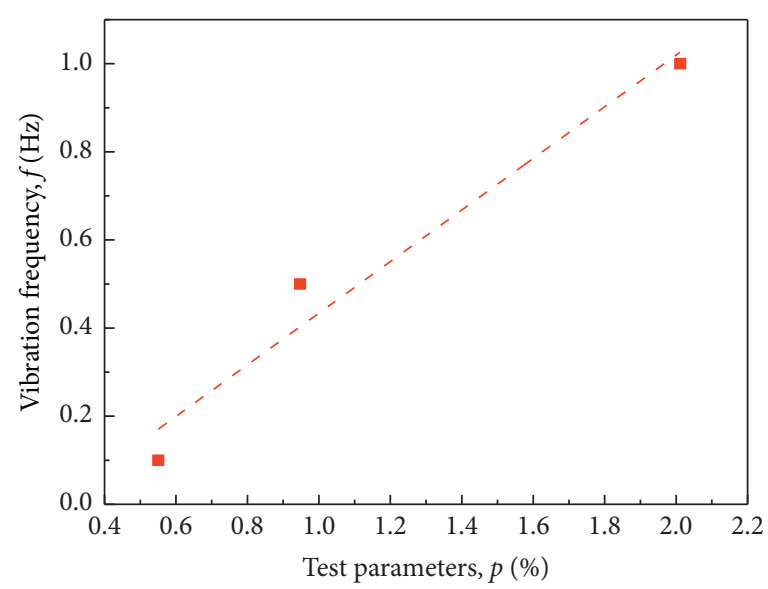

- Test

- - - Prediction

FigURE 17: Relationship between parameter $p$ and loading frequency $f$.
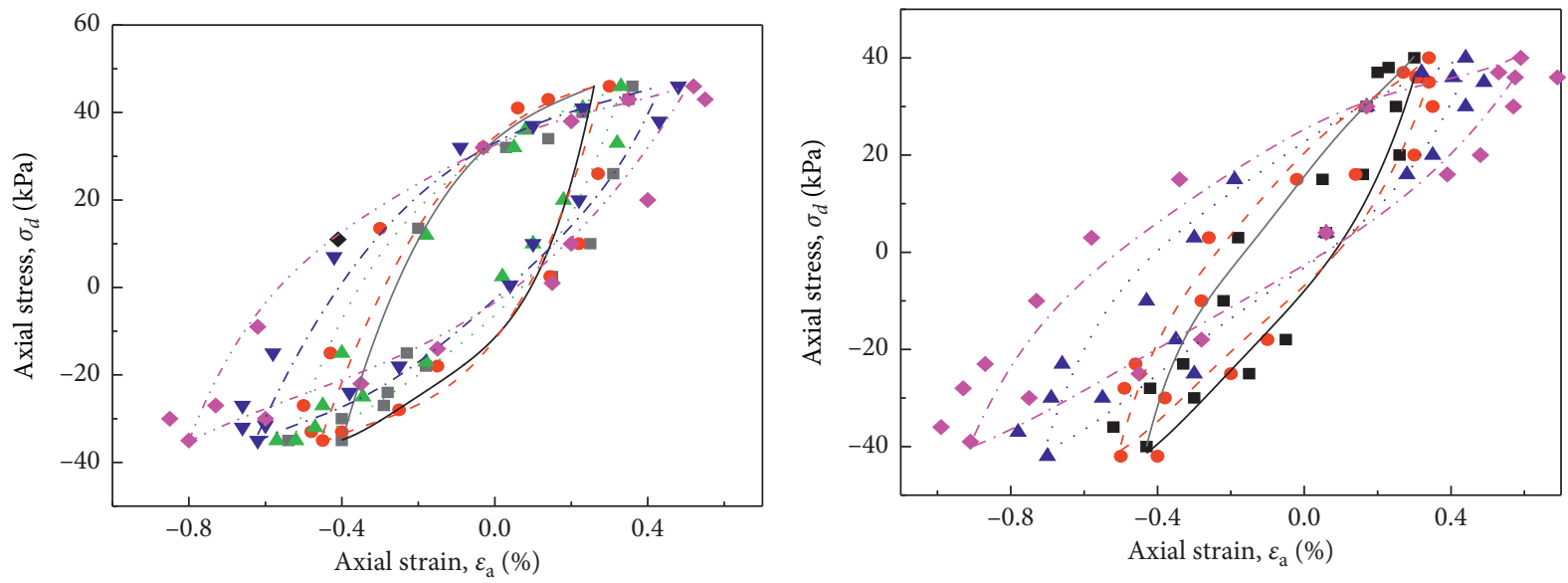

- $N=1$

_ Calculated data

- $N=1$

- Calculated

- $N=10$

- - Calculated data

- $N=10$

$\triangle N=100$

Calculated data

$\checkmark N=1000$

...- Calculated data

$\checkmark N=100$

Calculated

- $N=10000 \quad \cdots \quad$ Calculated data

- $N=1000 \quad-.-$ Calculated

(a)

(b)

Figure 18: Continued. 


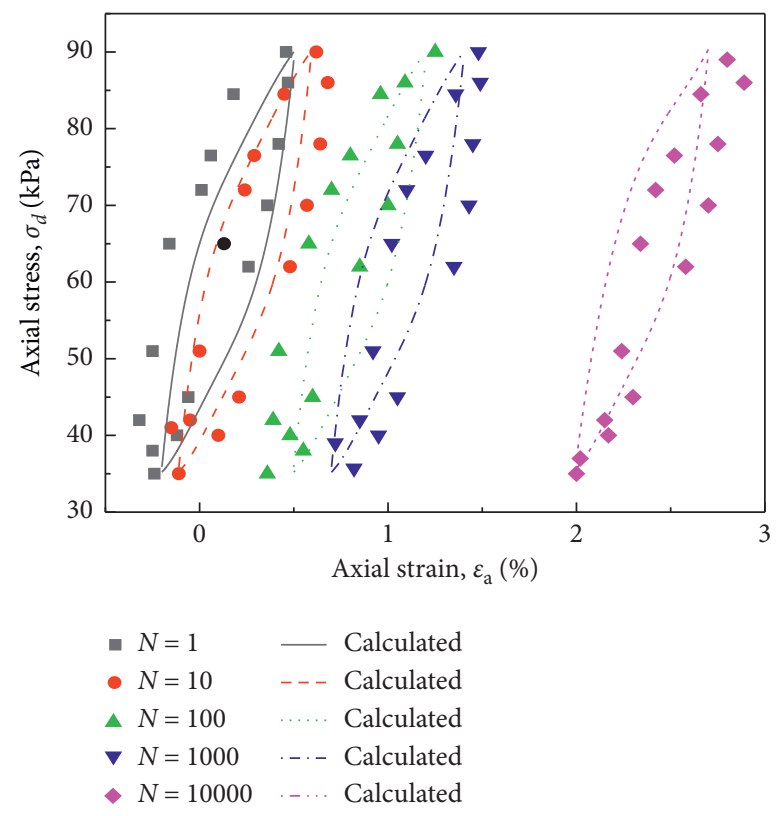

(c)

Figure 18: Application of accumulative plastic strain model on different soil samples: (a) A105, (b) A202, and (c) A301.

where $\varepsilon_{N}$ and $\varepsilon_{1}$ are the plastic strains loaded at the $N$ th and 1 st cycles, respectively, and $C$ and $\varsigma$ are the test constants.

$$
\delta=\frac{1}{1+p \zeta}
$$

where $p$ is the test parameter, and it is related to the frequency.

Figure 17 shows the relationship between the parameter $p$ and the loading frequency $f$. The following expression could be used to relate the above parameters as

$$
p=\frac{f+0.152}{0.586}
$$

Combining equations (8) and (11) into (10), the expression would be

$$
\begin{aligned}
\delta & =\frac{1}{1+(f+0.152 / 0.586)} \\
& =\frac{0.586}{0.586+(f+0.152)(1-1.156 \lg f) K_{0}{ }^{2.996} \varepsilon_{\mathrm{p}} / \mathrm{CSR}} .
\end{aligned}
$$

Then, the relationship between the accumulative plastic strain and degradation index can be obtained as

$$
\varepsilon_{p}=\frac{0.586(1 / \delta-1) C S R}{(f+0.152)(1-1.156 \lg f) K_{0}^{2.996}} .
$$

Equation (7) is brought into equation (13) to obtain the accumulative plastic strain degradation model of soft clay.

In addition, there is a normalized characteristic between $\varepsilon_{p}$ and $\delta$, which is determined by the nature of the soil and has a certain universality. In particular, for different soils, the selection of parameters needs to be determined according to specific tests.

\section{Validation}

At present, there are many constitutive models to describe the accumulative deformation of soil, among which the Iwan model is the most widely used, but this model cannot accurately reflect the cyclic degradation characteristics of soil and the increase in the accumulative strain [38]. As the number of cycles is small, the test value is in agreement with the measured value, but there is a large difference when the number of cycles increases. Hence, considering the effect of the accumulative plastic strain, an ideal rigid-plastic element is connected in series to reflect the accumulative strain during the cycle:

$$
\varepsilon=\varepsilon_{p}+\sum_{i=0}^{m} \frac{\sigma-\sigma_{i}^{*}}{\delta H_{i}}
$$

where $\sigma$ is the stress on each element; $\sigma_{i}^{*}$ is the yield stress of the unit; $H_{\mathrm{i}}$ is the plastic modulus of the $i$-th element spring.

Combining equations (7) and (11) into (12), the relationship between stress and strain of soft clay under cyclic load can be obtained. Figure 18 shows the described dynamic stress-strain relationship curve. It can be concluded that the calculated value is more consistent with the measured value, which proves the rationality of the cumulative plastic strain model in this paper.

\section{Conclusions}

According to the user-defined waveform, cyclic torsion shear (CTS) tests were carried out on undisturbed Hangzhou soft clay, and the influences of degradation index and 
accumulative plastic strain on the cyclic degradation characteristics of undisturbed soft clay under different cyclic stress ratios (CSR), deviatoric consolidation ratios $\left(K_{0}\right)$, and loading frequencies $f$ have been analyzed. The following conclusions are obtained:

Vertical dynamic stress amplitude $\sigma_{z}^{\text {ampl }}$, deviatoric consolidation ratios $K_{0}$, and loading frequency $f$ have significant impacts on the degradation degree of the tested soil. As the vertical dynamic stress amplitude, deviatoric consolidation ratios $K_{0}$, and loading frequency $f$ increase, the degradation index $\delta$ gradually decreases, and the degradation degree of the soil increases. Furthermore, when the vertical dynamic stress amplitude is large, the loading frequency has little effect on the degradation index.

The degradation index of the soil under the cyclic torsion shear (CTS) test is always higher than that under the cyclic triaxial (CT) test, which shows that the deflection of the principal stress axis will increase the degradation degree of the soil. By comparing the development law of degradation index under cyclic triaxial (CT) and cyclic torsion shear (CTS) test, the relationship between the degradation index under the cyclic torsion shear (CTS) test and the cyclic triaxial (CT) test is established: $\sigma_{\mathrm{HCA}}=1.4 a \ln N+0.994 b$.

The influence of the cyclic stress ratio (CSR), deviatoric consolidation ratios $K_{0}$, and loading frequency $f$ on the cumulative plastic deformation of soil cannot be ignored. The increase in the cyclic stress ratio (CSR), $K_{0}$ value, and the decrease in the loading frequency promote the initial accumulative plastic strain of the soil sample and accelerate the failure rate of the soil sample.

In the low-frequency range $(f=0.15)$, the decrease in the loading frequency significantly increases the strain growth rate and accelerates the failure rate of the soil sample. However, in the high-frequency range $(f \geq 0.5)$, the relationship between the degradation index and the accumulative plastic strain at different frequencies gradually becomes similar.

An accumulative plastic strain-degradation model for describing the undisturbed soft clay is established. It comprehensively considers the effects of cyclic stress ratio (CSR), deviatoric consolidation ratios $K_{0}$, and loading frequency $f$ on the accumulative deformation of the soil and could reflect the cyclic softening characteristics of the soil and the increase in the accumulative plastic strain. The revised Iwan model is used to verify the rationality of the proposed model. It is believed that the model can provide a theoretical basis for predicting and calculating the long-term settlement and deformation of the foundation soil.

\section{Data Availability}

The data used to support the findings of this study are included within the article.

\section{Conflicts of Interest}

The authors declare that they have no conflicts of interest.

\section{Acknowledgments}

This work was supported by the Zhejiang Natural Science Foundation (Nos. LY18E080024, LY18E080026, and LHZ20E080001) and the Key Research and Development Project of Zhejiang Province (No. 2020C01102). Their financial supports are gratefully acknowledged.

\section{References}

[1] A. J. Puppala, L. N. Mohammad, and A. Allen, "Permanent deformation Characterization of subgrade soils from RLT test," Journal of Materials in Civil Engineering, vol. 11, no. 4, pp. 274-282, 1999.

[2] L. Guo, Y. Cai, R. J. Jardine, Z. Yang, and J. Wang, "Undrained behaviour of intact soft clay under cyclic paths that match vehicle loading conditions," Canadian Geotechnical Journal, vol. 55, no. 1, pp. 90-106, 2017.

[3] R. P. Dai, "Study on cumulative settlement of cross-river tunnel of Hangzhou Metro line 1," Modern Urban Transit, vol. 3, pp. 57-61, 2014.

[4] Z. C. Wang, Y. C. Zhao, Q. Yang et al., "Analysis on the reasons of non-uniform settlement of shield tunnel and the response measures," Journal of Water Resources and Architectural Engineering, vol. 14, no. 4, pp. 53-58, 2019, (in chinese).

[5] J. H. Wang and M. L. Yao, "The elastic-plastic simulation of soft clay's undrained cyclic characteristic," Journal of Zhejiang University, vol. 18, no. 3, pp. 11-18, 1996, (in chinese).

[6] C. L. Monismith, N. Ogawa, and C. R. Freeme, "Permanent deformation characteristics of subgrade soils due to repeated loading," Transportation Research Record Journal.vol. 537, pp. 1-17, 1975.

[7] D. Li and E. T. Selig, "Cumulative plastic deformation for finegrained subgrade soils," Journal of Geotechnical Engineering, vol. 122, no. 12, pp. 1006-1013, 1996.

[8] D. Li and E. T. Selig, "Method for railroad track foundation design. II: applications," Journal of Geotechnical and Geoenvironmental Engineering, vol. 124, no. 4, pp. 323-329, 1998.

[9] G. Gidel, P. Hornych, J. J. Chauvin, D. Breysse, and A. Denis, "A new approach for investigating the permanent deformation behavior of unbound granular material using the repeated load triaxial apparatus," Bullettin Labaratory Bridges Roads, vol. 233, no. 4, pp. 5-21, 2001.

[10] J.-C. Chai and N. Miura, "Traffic-load-induced permanent deformation of road on soft subsoil," Journal of Geotechnical and Geoenvironmental Engineering, vol. 128, no. 11, pp. 907-916, 2002.

[11] J. Wang, L. Guo, Y. Cai, C. Xu, and C. Gu, "Strain and pore pressure development on soft marine clay in triaxial tests with a large number of cycles," Ocean Engineering, vol. 74, no. 12, pp. 125-132, 2013.

[12] X.-W. Ren, Q. Xu, J. Teng, N. Zhao, and L. Lv, “A novel model for the cumulative plastic strain of soft marine clay under long-term low cyclic loads," Ocean Engineering, vol. 149, pp. 194-204, 2018.

[13] G. T. H. Sweere, "Unbound granular bases for roads," PH. D. thesis, Univeristy of Delft, Delft, Netherlands, 1990. 
[14] M. J. Shenton, "Deformation of railway ballast under repeated loading conditions," Railroad Track Mechanics and Technology, vol. 405, 1978.

[15] R. W. Lentz and G. Y. Baladi, "Constitutive equation for permanent strain of sand subjected to cyclic loading," Transportation Research Record Journal, vol. 810, pp. 50-54, 1981.

[16] Y. Cai, Q. Sun, L. Guo, C. H. Juang, and J. Wang, "Permanent deformation characteristics of saturated sand under cyclic loading," Canadian Geotechnical Journal, vol. 52, no. 6, pp. 795-807, 2015.

[17] A. F. L. Hyde and S. F. Brown, "The plastic deformation of a silty clay under creep and repeated loading," Géotechnique, vol. 26, no. 1, pp. 173-184, 1976.

[18] N. Matasovic and M. Vucetic, "Generalized cyclic degradation pore pressure generation model for clays," Journal of Geotechnical Engineering, vol. 121, no. 1, pp. 33-42, 1995.

[19] L. Tang, H. Chen, H. Sang, S. Zhang, and J. Zhang, "Determination of traffic-load-influenced depths in clayey subsoil based on the shakedown concept," Soil Dynamics and Earthquake Engineering, vol. 77, pp. 182-191, 2015.

[20] Y. Cai, T. Wu, L. Guo, and J. Wang, "Stiffness degradation and plastic strain accumulation of clay under cyclic load with principal stress rotation and deviatoric stress variation," Journal of Geotech Geoenviron Engineering, vol. 144, 2018.

[21] T. Wu, Y. Cai, L. Guo, D. Ling, and J. Wang, "Influence of shear stress level on cyclic deformation behaviour of intact Wenzhou soft clay under traffic loading," Engineering Geology, vol. 228, no. 10, pp. 61-70, 2017.

[22] Q. Sun, Q. Dong, Y. Cai, and J. Wang, "Modeling permanent strains of granular soil under cyclic loading with variable confining pressure," Acta Geotechnica, vol. 15, no. 6, p. 1409, 2019.

[23] Y. Li, M. Wei, L. Liu, Q. Xue, and B. Yu, "Adsorption of toluene on various natural soils: influences of soil properties, mechanisms, and model," Science of The Total Environment, vol. 740, Article ID 140104, 2020.

[24] T. Lunne, T. Berre, K. H. Andersen, S. Strandvik, and M. Sjursen, "Effects of sample disturbance and consolidation procedures on measured shear strength of soft marine Norwegian clays," Canadian Geotechnical Journal, vol. 43, no. 7, pp. 726-750, 2006.

[25] D. W. Hight, A. Gens, and M. J. Symes, "The development of a new hollow cylinder apparatus for investigating the effects of principal stress rotation in soils," Géotechnique, vol. 33, no. 4, pp. 355-383, 1983.

[26] A. W. Skempton, "The pore-pressure Coefficients A and B," Géotechnique, vol. 4, no. 4, pp. 143-147, 1954.

[27] S.-H. Hyde, H.-F. Shan, T.-D. Xia, Z.-J. Liu, Z. Ding, and F. Xia, "The effect of temperature on the drained shear behavior of calcareous sand," Acta Geotechnica, vol. 21, 2020.

[28] S.-H. He, Q.-F. Zhang, Z. Ding, T.-D. Xia, and X.-L. Gan, "Experimental and estimation studies of resilient modulus of marine coral sand under cyclic loading," Journal of Marine Science and Engineering, vol. 8, no. 4, p. 287, 2020.

[29] Y. Cai, L. Guo, R. J. Jardine, Z. Yang, and J. Wang, "Stress-strain response of soft clay to traffiffiffic loading," Geotechnique, vol. 67, pp. 446-451, 2016.

[30] I. M. Idriss, R. Dobry, and R. D. Singh, "Nonlinear behavior of soft clays during cyclic loading," Journal of Geotechnical Engineering, vol. 104, no. 12, pp. 1427-1447, 1978.

[31] J. Zhou and X. N. Gong, "Study on strain softening in saturated soft clay under cyclic loading," China Civil Engineering Journal, vol. 33, no. 5, pp. 75-78, 2000, in Chinese.
[32] K. Yasuhara, A. F. L. Hyde, N. Toyota et al., "Cyclic stiffness of plastic silt with an initial drained shear stress," in Proceedings of the Geotechnique Symptom on Pre-failure Deformation of Geomaterials, pp. 373-382, London, UK, July 1998.

[33] F. Lekarp, U. Isacsson, and A. Dawson, "State of the art. II: permanent strain response of unbound aggregates," Journal of Transportation Engineering, vol. 126, no. 1, pp. 76-83, 2000.

[34] L. Guo, J. Wang, Y. Cai, H. Liu, Y. Gao, and H. Sun, "Undrained deformation behavior of saturated soft clay under long-term cyclic loading," Soil Dynamics and Earthquake Engineering, vol. 50, pp. 28-37, 2013.

[35] R. Zhang, Y. J. Tu, W. P. Fei et al., "Effect of vibration frequency on dynamic properties of saturated cohesive soil," Rock and Soil Mechanics, vol. 27, no. 5, pp. 699-704, 2006, in Chinese.

[36] K. Yasuhara and K. Hirao, "Effects of cyclic loading on undrained strength and compressibility of clay," Soils and Foundations, vol. 32, no. 1, pp. 100-116, 1972.

[37] T. Matsui, T. Ito, and H. Ohara, "Cyclic stress-strain history of and shear characteristics of clay," Journal of the Geotechnical Engineering Division, vol. 106, no. 10, pp. 1101-1120, 1980.

[38] S. N. Rao and A. P. Panda, "Non-linear analysis of undrained cyclic strength of soft marine clay," Ocean Engineering, vol. 26, pp. 241-253, 1999. 